\title{
Anthropogenically enhanced fluxes of water and carbon from the Mississippi River
}

\author{
Peter A. Raymond ${ }^{1 *}$, Neung-Hwan Oh ${ }^{1 *}$, R. Eugene Turner ${ }^{2} \&$ Whitney Broussard ${ }^{3}$
}

The water and dissolved inorganic carbon exported by rivers are important net fluxes that connect terrestrial and oceanic water and carbon reservoirs ${ }^{1}$. For most rivers, the majority of dissolved inorganic carbon is in the form of bicarbonate. The riverine bicarbonate flux originates mainly from the dissolution of rock minerals by soil water carbon dioxide, a process called chemical weathering, which controls the buffering capacity and mineral content of receiving streams and rivers ${ }^{2}$. Here we introduce an unprecedented high-temporal-resolution, 100-year data set from the Mississippi River and couple it with sub-watershed and precipitation data to reveal that the large increase in bicarbonate flux that has occurred over the past $\mathbf{5 0}$ years (ref. 3 ) is clearly anthropogenically driven. We show that the increase in bicarbonate and water fluxes is caused mainly by an increase in discharge from agricultural watersheds that has not been balanced by a rise in precipitation, which is also relevant to nutrient and pesticide fluxes to the Gulf of Mexico. These findings demonstrate that alterations in chemical weathering are relevant to improving contemporary biogeochemical budgets. Furthermore, land use change and management were arguably more important than changes in climate and plant $\mathrm{CO}_{2}$ fertilization to increases in riverine water and carbon export from this large region over the past 50 years.

The riverine bicarbonate flux is a sink for atmospheric $\mathrm{CO}_{2}$ and a small but important net flux in terrestrial systems. In the preindustrial era, chemical weathering of silicate versus carbonate minerals sequestered $\mathrm{CO}_{2}$ for disparate timescales owing to carbonate deposition in the oceans, with silicate weathering sequestering atmospheric $\mathrm{CO}_{2}$ for millions of years and carbonate weathering for only tens to hundreds of thousands of years ${ }^{4}$. Oceanic acidification ${ }^{5}$, however, has changed the solubility of $\mathrm{CaCO}_{3}$, and considerably lengthened the timescale for $\mathrm{CO}_{2}$ sequestration by carbonate weathering. Although the positive feedbacks between global change and chemical weathering are used in geochemical models of atmospheric $\mathrm{CO}_{2}$ (ref. 6), these feedbacks are believed to operate on long timescales and are therefore generally left out of the current discussion on human alterations of the carbon budget. Current global carbon budgets, for example, assume that pre- and post-anthropogenic riverine carbon fluxes are equal ${ }^{1}$.

There are two ways to increase the flux of bicarbonate from rivers. The first is to increase discharge. Although bicarbonate and most major cations/anions dilute with increasing discharge $e^{7,8}$, the dilution factor in many watersheds, including the Mississippi River basin (MRB), is small, and the flux of bicarbonate increases at higher discharge ${ }^{9}$. The second way is to alter the relationship between discharge and carbon export, so that a higher carbon export is realized at the same discharge (Supplementary Information). Changes in this export:discharge relationship can be determined by normalizing fluxes to the rate of discharge ${ }^{10,11}$, which we do here by calculating the bicarbonate flux at average discharge $\left(F_{\text {avgD }}\right.$; Supplementary Information). In the Mississippi River, the bicarbonate flux and $F_{\text {avgD }}$ show large increases from 1902 to 2005 (Fig. 1). Importantly, $F_{\text {avgD }}$ begins to rise above the early century values around the mid1950s (Fig. 1), resulting in a $2.9 \mathrm{Tg}$ (Fig. 1 legend) larger flux during an average annual discharge year at the end of the century (Fig. 1). The 4.6 Tg (Fig. 1 legend) increase in flux lags considerably behind the increase in the $F_{\text {avgD }}$ because there was a period of low discharge in the 1950s and 1960s (Fig. 1). Raymond and Cole ${ }^{3}$ analysed a 19542001 United States Geological Survey (USGS) data set and concluded that the increase in bicarbonate flux was due mainly to an increase in discharge. This conclusion, however, was biased by a decade of relatively low flow corresponding with the start of the USGS data set. Studies that have analysed smaller temporal data sets, and not normalized for discharge, have also not found these changes in bicarbonate, because of the large annual variation in bicarbonate concentration and flux ${ }^{12}$. The new and higher resolution data presented here corroborate the USGS data set (Supplementary Information), yet indicate that changes in the $F_{\mathrm{avgD}}$ are responsible for $63 \%$ of the increase in flux (2.9 Tg of $4.6 \mathrm{Tg}$; Fig. 1 legend). This is an important distinction, which demonstrates that internal watershed modifications, discussed below, are causing a considerable change in the flux of bicarbonate and other constituents from North America's largest river.

Our sub-watershed analysis indicates that the bicarbonate flux in a large portion of the MRB is transport limited (Fig. 2). In transport limited systems, soil water ion concentrations are at or near saturation with soil minerals because of low water throughput and long water residence times ${ }^{13-15}$. As concentrations are at saturation and cannot be raised, this places a hydrologic constraint on the ability of additional acid generating processes (for example, soil respiration) to increase the bicarbonate $F_{\mathrm{avgD}}$. There is no substantial increase in the $F_{\text {avgD }}$ in sub-watersheds receiving less than $\sim 0.6 \mathrm{~m}$ of rain, indicating severe transport limitation (Fig. 2). Watersheds receiving between 0.5 and $1 \mathrm{~m}$ of rain demonstrate mild transport limitation (Fig. 2). Although it is difficult to raise the rate of bicarbonate export by increasing the input of weathering agents (for example, $\mathrm{CO}_{2}$ ) in transport limited watersheds, they are poised to respond to increases in discharge.

Similar to previous studies ${ }^{16,17}$, our analysis demonstrates an increase in discharge for many gauging stations in the MRB (Fig. 3; Supplementary Fig. 4). Interestingly, by coupling watershed discharge and precipitation, we find that the discharge increases are only partly explained by concomitant precipitation increases (Fig. 3). A larger percentage of the increase in discharge, particularly in agricultural watersheds, can be explained by changes in discharge at average precipitation (Fig. 3). An increase in the discharge at average precipitation demonstrates that modifications of watershed properties are

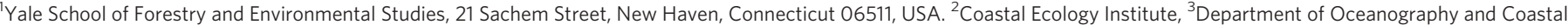
Sciences, Louisiana State University, Baton Rouge, Louisiana 70803, USA.

*These authors contributed equally to this work. 
changing the relationship between precipitation and discharge, causing the amount of discharge to increase in a normal precipitation year (Supplementary Information). It is important to control for precipitation by calculating the discharge at the average precipitation, because the discharge:precipitation ratio naturally fluctuates with varying precipitation in a given watershed ${ }^{9}$. Authors have argued that whole watershed response to vegetation $\mathrm{CO}_{2}$ fertilization should be causing increases in discharge and in the discharge:precipitation ratio
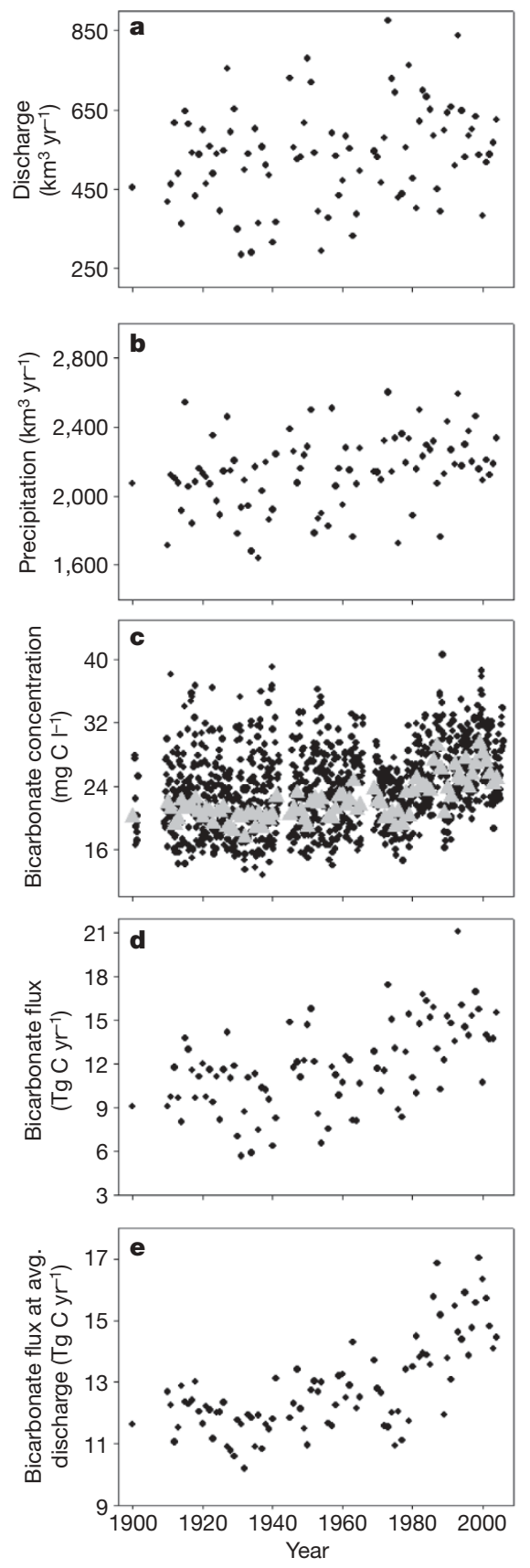

Figure 1 | Mississippi watershed fluxes and bicarbonate concentrations. a, Discharge; $\mathbf{b}$, precipitation; $\mathbf{c}$, bicarbonate concentration; $\mathbf{d}$, bicarbonate flux; e, bicarbonate flux at average discharge $\left(F_{\mathrm{avgD}}\right)$. Concentrations represent monthly averages (black filled circles), with annual averages shown as grey filled triangles, while fluxes are all annual. The average values for pre-disturbance $(<1940)$ are $494 \mathrm{~km}^{3}, 2,047 \mathrm{~km}^{3}, 20.3 \mathrm{mgl}^{-1}, 10.0 \mathrm{Tg}$ and $11.8 \mathrm{Tg}$ for discharge, precipitation, concentration, flux and $F_{\text {avgD }}$, respectively. The post-disturbance $(>1980)$ era values are $578 \mathrm{~km}^{3}$, $2,239 \mathrm{~km}^{3}, 25.4 \mathrm{mgl}^{-1}, 14.6 \mathrm{Tg}$ and $14.7 \mathrm{Tg}$, resulting in changes of $84 \mathrm{~km}^{3}$, $192 \mathrm{~km}^{3}, 5.1 \mathrm{mgl}^{-1}, 4.6 \mathrm{Tg}$ and $2.9 \mathrm{Tg}$, for discharge, precipitation, concentration, flux and $F_{\text {avgD }}$, respectively.

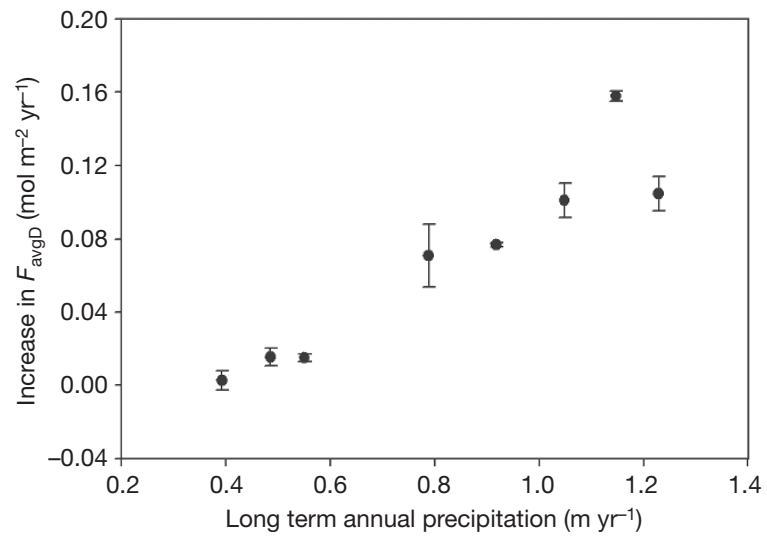

Figure 2 | Bin-averaged relationships between the increase in $\boldsymbol{F}_{\text {avgd }}$ and annual precipitation for sub-watersheds of the Mississippi. Non-responses from watersheds with low $\left(<0.6 \mathrm{~m} \mathrm{yr}^{-1}\right)$ levels of precipitation are an indication of transport limitation. Only watersheds that had an increase in $F_{\text {avgD }}$ were used. The error bars are \pm 1 s.e. ( $n=6$ for each bin). The precipitation bins are $0.33-0.42 \mathrm{~cm}, 0.45-0.53 \mathrm{~cm}, 0.54-0.57 \mathrm{~cm}$, $0.58-0.90 \mathrm{~cm}, 0.91-0.93 \mathrm{~cm}, 0.94-1.12 \mathrm{~cm}, 1.12-1.17 \mathrm{~cm}$ and $1.19-1.36 \mathrm{~cm}$.

by decreasing evapotranspiration ${ }^{18,19}$. Here we show that agricultural practices may have a stronger signal in the latter half of the twentieth century for a large river that integrates much of temperate North America. It is important to note that in forested watersheds of the $M R B$, increases in discharge are highly correlated with increases in precipitation (Fig. 3 legend) and not with discharge at average precipitation.

There is a strong correlation between the percentage land-cover in agriculture and the size of both the increase in discharge and the change in discharge at average precipitation (Fig. 4). We argue that the relationship between agricultural land cover and the change in discharge at average precipitation demonstrates that agricultural practices are increasing river discharge. This finding is consistent with recent studies arguing for an acceleration of the water budget of the Mississippi River due to changes in agricultural practices over
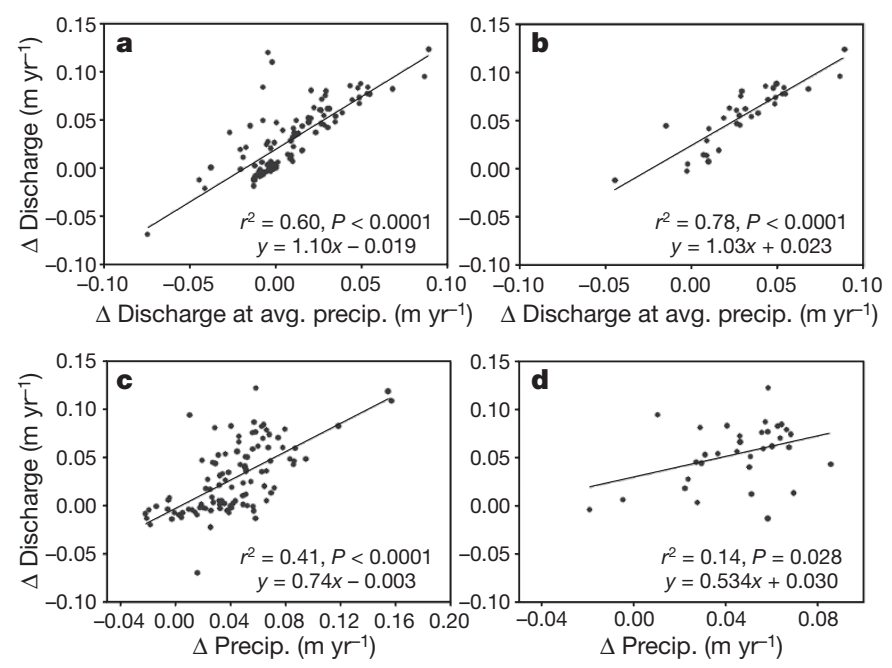

Figure 3 | Change in discharge versus change in discharge at average precipitation and change in precipitation for sub-watersheds of the Mississippi. The left panels show all watersheds, while the right panels show only watersheds with $70 \%$ or greater cropland land cover. The change was calculated by grouping the data before 1966 and after 1987. It is important to note that in sites with low agricultural cover $(<30 \%)$, change in precipitation predicts $74 \%$ of the variation in change in discharge, while change in discharge at average precipitation can only predict $25 \%$ - that is, in forested watersheds changes in precipitation do balance changes in discharge. 


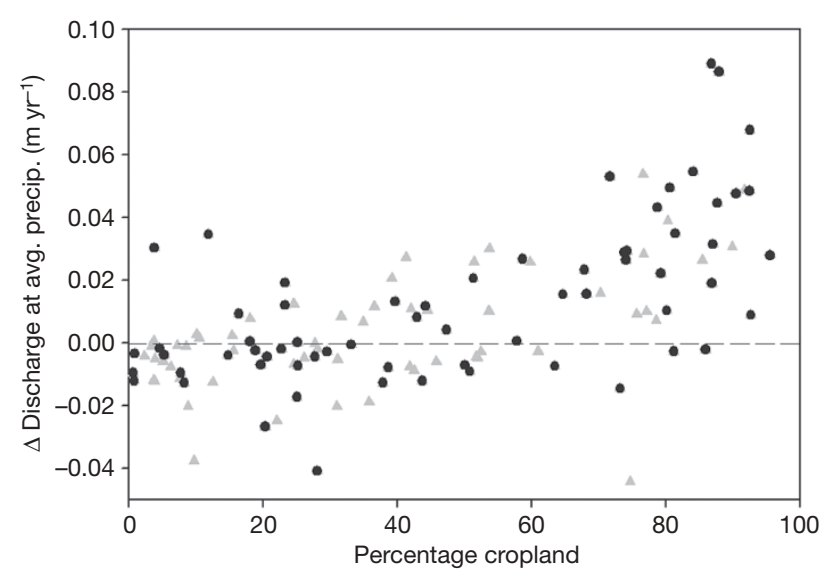

Figure 4 | The change in discharge at average precipitation versus the percentage of land-cover designated as cropland for sub-watersheds of the Mississippi. The change was calculated by averaging the time periods $<1966$ and $>1987$. The black filled circles represent watersheds that are independent, while the grey filled triangles are watersheds that have nested watersheds within them.

similar time periods ${ }^{20,21}$. Remembering that these agricultural landscapes are highly modified, have soils that are well buffered and moderately transport limited, and therefore have high concentrations of bicarbonate and other important biogeochemical constituents ${ }^{22}$, this amounts to significant increases in fluxes from the US cropland centres. Agricultural liming is undoubtedly playing a role in the increased bicarbonate fluxes ${ }^{23-25}$, although the impact of liming will be hydrologically constrained in transport limited watersheds.

We can use the data presented here to scale the potential ramifications of increased discharge, due to agricultural practices, on water and bicarbonate fluxes. If one assumes that $42 \%$ of the Mississippi watershed is cropland (Supplementary Information) and that there is on average a $4 \mathrm{~cm}$ (Fig. 4) increase in discharge not balanced by precipitation on this land-cover, then the annual increase in discharge not balanced by precipitation is $49 \mathrm{~km}^{3}$. If we assume that average bicarbonate concentrations from croplands are $\sim 50 \mathrm{mg} \mathrm{Cl}^{-1}$ (ref. 3), the result is an additional $2.4 \mathrm{Tg} \mathrm{yr}^{-1}$ of bicarbonate, or about $52 \%$ of the increase in flux found in this study. Owing to the much higher bicarbonate yields from these well buffered agricultural soils, increasing the proportion of water originating from croplands will account for $84 \%$ of the increase in the $F_{\text {avgD }}$ (Fig. 1). The high concentrations of bicarbonate $\left(50 \mathrm{mg} \mathrm{Cl}^{-1}\right)$ in cropland rivers and streams are also partly due to agricultural practices like liming ${ }^{23-25}$, and therefore agricultural practices that have raised bicarbonate concentrations are also partly captured in these estimates. Precipitation has increased by $190 \mathrm{~km}^{3}(\sim 9 \%)$ over this same time period (Fig. 1), which is consistent with estimated values ${ }^{26}$. Using a pre-disturbance discharge:precipitation ratio of $\sim 0.24$ (Fig. 1) and a pre-disturbance Mississippi River bicarbonate concentration of $20.3 \mathrm{mg} \mathrm{Cl}^{-1}$ (Fig. 1) results in an increase in flux of $0.94 \mathrm{Tg}$ due to precipitation increases, which is $\sim 20 \%$ of the observed increase in flux. Thus, in the MRB, despite a 9\% increase in precipitation, the anthropogenic forcing has outweighed the climatic forcing in the past 50 years. The remaining $30 \%$ of the increase in bicarbonate flux is due to other mechanisms, such as recovery from acidification $^{27}$, and anthropogenic alterations that allow for a greater response to precipitation post-disturbance.

We argue that changes in agricultural practices have had drastic impacts on the net chemistry and hydrology of the Mississippi. With respect to the discharge increase, agricultural practices have led to an increase of discharge on the scale of $\sim 50 \mathrm{~km}^{3} \mathrm{yr}^{-1}$ (for comparison, the discharge of the Susquehanna and Rhone rivers are $\sim 30$ and $54 \mathrm{~km}^{3} \mathrm{yr}^{-1}$, respectively). Potential agricultural practices that might be altering discharge are tile drainage, fertilizer use, irrigation, tillage practices, and changes in crop type ${ }^{20,21}$, rotation and productivity. These changes, coupled with precipitation increases and the use of lime, have led to a large increase in alkalinity flux. Large scale changes to crop production to meet proposed ethanol production may continue to alter cropland water and carbon export. Furthermore, bicarbonate is the major anion in streams and rivers and is linked to many other element cycles, so large scale changes in bicarbonate demand compensating changes in other important ions, such as calcium and silica $^{28}$. Finally, any element (for example, nitrogen or phosphorus) ${ }^{22,29}$ or pollutant ${ }^{22,29}$ that has elevated fluxes due to agricultural practices is undoubtedly also being affected by the increase in discharge from agricultural watersheds, potentially on a similar scale to those reported here for bicarbonate.

\section{METHODS SUMMARY}

The data set used here for the Mississippi River represents tens of thousands of measurements over 100 years, and is therefore the most complete long-term data set for riverine carbon for a major world river ever reported and a data set of primary importance with respect to understanding global change issues. The data originate from the Carrollton and Algiers Water Purification Plants, operated by the Sewage and Water Board of New Orleans, where alkalinity is measured to determine how much lime to add as Mississippi River water is processed for the city. The plants have made multiple measurements of bicarbonate, as alkalinity (Supplementary Information), per day for the past 40 years, and perhaps the past 105 years, although only the monthly averages are available from 1902 to 1961. See Supplementary Information for further discussion of the raw data. The second data set was 106 USGS sub-watersheds that had long-term records of discharge, 84 USGS sites with long-term river chemistry data (augmented with historic data from the state of Illinois water survey to increase the number of agricultural sites), and precipitation data from the PRISM Group, Oregon State University. Explanations and examples of how fluxes were calculated are provided in Supplementary Information.

\section{Received 6 July; accepted 23 November 2007.}

1. Sabine, C. L. et al. in The Global Carbon Cycle (eds Field, C. B. \& Raupack, M. R.) Ch. 2 (Island Press, Washington, 2004)

2. Gaillardet, J., Dupre, B., Louvat, P. \& Allegre, C. J. Global silicate weathering and $\mathrm{CO}_{2}$ consumption rates deduced from the chemistry of large rivers. Chem. Geol. 159, 3-30 (1999)

3. Raymond, P. A. \& Cole, J. J. Increase in the export of alkalinity from North America's largest river. Science 301, 88-91 (2003).

4. Berner, R. A., Lasaga, A. C. \& Garrels, R. M. The carbonate-silicate geochemical cycle and its effect on atmospheric carbon dioxide over the past 100 million years. Am. J. Sci. 283, 641-683 (1983).

5. Feely, R. A. et al. Impact of anthropogenic $\mathrm{CO}_{2}$ on the $\mathrm{CaCO}_{3}$ system in the oceans. Science 305, 362-366 (2004).

6. Berner, R. A. The Phanerozoic Carbon Cycle (Oxford Univ. Press, Oxford, 2004).

7. Shanley, J. B., Kendall, C., Smith, T. E., Wolock, D. M. \& McDonnell, J. J. Controls on old and new water contributions to stream flow at some nested catchments in Vermont, USA. Hydrol. Process. 16, 589-609 (2002).

8. Jarvie, H. P. et al. Major ion concentrations and the inorganic carbon chemistry of the Humber rivers. Sci. Total Environ. 194, 285-302 (1997).

9. Raymond, P. A. \& Oh, N. H. An empirical study of climatic controls on riverine C export from three major U.S. watersheds. Glob. Biogeochem. Cycles 21, GB2022, doi:10.1029/2006GB002783 (2007).

10. Murdoch, P. S. \& Shanley, J. B. Flow-specific trends in river-water quality resulting from the effects of the clean air act in three mesoscale, forested river basins in the northeastern United States through 2002. Environ. Monit. Assess. 120, 1-25 (2006).

11. Striegl, R. G., Aiken, G. R., Dornblaser, M. M., Raymond, P. A. \& Wickland, K. P. A decrease in discharge-normalized DOC export by the Yukon River during summer through autumn. Geophys. Res. Lett. 32, L21413, doi:10.1029/2005GL024413 (2005).

12. Jones, J. B., Stanley, E. H. \& Mulholland, P. J. Long-term decline in carbon dioxide supersaturation in rivers across the contiguous United States. Geophys. Res. Lett. 30, 1495-1499 (2003)

13. Kump, L. R., Brantley, S. L. \& Arthur, M. A. Chemical weathering, atmospheric $\mathrm{CO}_{2}$, and climate. Annu. Rev. Earth Planet. Sci. 28, 611-667 (2000).

14. Szramek, K. \& Walter, L. M. Impact of carbonate precipitation on riverine inorganic carbon mass transport from a mid-continent, forested watershed. Aquat. Geochem. 10, 99-137 (2004).

15. Williams, E. L., Szramek, K. J., Jin, L. X., Ku, T. C. W. \& Walter, L. M. Carbonate system geochemistry of shallow groundwater-surface water systems in temperate glaciated watersheds (Michigan, USA): Significance of open-system dolomite weathering. Geol. Soc. Am. Bull. 119, 515-528 (2007). 
16. Lins, H. F. \& Slack, J. R. Seasonal and regional characteristics of US streamflow trends in the United States from 1940 to 1999. Phys. Geogr. 26, 489-501 (2005).

17. Lins, H. F. \& Slack, J. R. Streamflow trends in the United States. Geophys. Res. Lett 26, 227-230 (1999).

18. Betts, R. A. et al. Projected increase in continental runoff due to plant responses to increasing carbon dioxide. Nature 448, 1037-1041 (2007).

19. Gedney, N. et al. Detection of a direct carbon dioxide effect in continental river runoff records. Nature 439, 835-838 (2006).

20. Zhang, Y. K. \& Schilling, K. E. Increasing streamflow and baseflow in Mississippi River since the 1940s: Effect of land use change. J. Hydrol. 324, 412-422 (2006).

21. Schilling, K. E. Relation of baseflow to row crop intensity in lowa. Agric. Ecosyst. Environ. 105, 433-438 (2005).

22. Turner, R. E. \& Rabalais, N. N. Changes in Mississippi River water quality this century. Bioscience 41, 140-147 (1991).

23. Hamilton, S. K., Kurzman, A. L., Arango, C., Jin, L. X. \& Robertson, G. P. Evidence for carbon sequestration by agricultural liming. Glob. Biogeochem. Cycles 21, GB2021, doi:10.1029/2006GB002738 (2007).

24. Oh, N. H. \& Raymond, P. A. Contribution of agricultural liming to riverine bicarbonate export and $\mathrm{CO}_{2}$ sequestration in the Ohio River basin. Glob. Biogeochem. Cycles 20, GB3012, doi:10.1029/2005GB00265 (2006).
25. West, T. O. \& McBride, A. C. The contribution of agricultural lime to carbon dioxide emissions in the United States: dissolution, transport, and net emissions. Agric. Ecosyst. Environ. 108, 145-154 (2005)

26. Watson, R. T. (ed.) Climate Change 2001: Synthesis Report (Cambridge Univ. Press, Cambridge, UK, 2001).

27. Stoddard, J. L. et al. Regional trends in aquatic recovery from acidification in North America and Europe. Nature 401, 575-578 (1999).

28. Stumm, W. \& Morgan, J. J. Aquatic Chemistry (Wiley and Sons, New York, 1996).

29. Pereira, W. E. \& Hostettler, F. D. Nonpoint-source contamination of the Mississippi River and its tributaries by herbicides. Environ. Sci. Technol. 27, 1542-1552 (1993).

Supplementary Information is linked to the online version of the paper at www.nature.com/nature.

Acknowledgements We thank M. Russell and the countless number of individuals from the Carrollton and Algiers Water Purification Plants who have performed titrations over the past century. F. Darby helped with assimilating this data. We thank the Yale FES, YIBS and Yale CEO for support in this effort. This work is supported by an NSF-Ecosystems CAREER grant, a NOAA CSCOR grant, and a Louisiana Board of Regents fellowship (W.B.).

Author Information Reprints and permissions information is available at www.nature.com/reprints. Correspondence and requests for materials should be addressed to P.A.R. (peter.raymond@yale.edu). 